This is the peer reviewed version of the following article: [A. Rahmanudin; X. A.

Jeanbourquin; S. Hanni; A. Sekar; E. Ripaud et al. : Morphology stabilization strategies for small-molecule bulk heterojunction photovoltaics. Journal Of Materials Chemistry A. 2017. DOI : 10.1039/c7ta05405j.], which has been published in final form at [https://dx.doi.org/10.1039/c7ta05405j]. This article may be used for non-commercial purposes in accordance with RSC Terms and Conditions for Self-Archiving.

\title{
Morphology stabilization strategies for small-molecule bulk heterojunction photovoltaics
}

\author{
Aiman Rahmanudin, Xavier A. Jeanbourquin, Simon Hänni, Arvindh Sekar, Emilie Ripaud, Liang Yao, and Kevin Sivula*
}

The greater crystallinity of solution-processed small-molecule organic semiconductors, compared to their polymer counterparts, renders the bulk heterojunction (BHJ) more susceptible to phase separation under thermal stress, decreasing device performance. Here we demonstrate and compare strategies to stabilize the donor:acceptor $\mathrm{BHJ}$ in $\mathrm{DPP}(\mathrm{TBFu})_{2}: \mathrm{PC}{ }_{61} \mathrm{BM}$ solar cells using molecular additives designed to either afford compatiblization (CP) of the bulk heterojunction, or to in-situ link (ISL) the components using a functional azide group. Both additives were found to stop phase segregation of the BHJ under thermal stress. At $5 \mathrm{wt} \%$ loading the ISL additive prevents phase segregation, while altering the azide reaction mechanism by using UV-induced linking versus thermal induced linking was found to significantly affect the device performance. Including $5 \mathrm{wt} \%$ of the $\mathrm{CP}$ additive slowed phase segregation and devices retained $80 \%$ of their optimum performance after $3000 \mathrm{~min}$ of thermal treatment at $110^{\circ} \mathrm{C}$ (compared to $50 \%$ with the control). The $\mathrm{CP}$ additive at $10 \mathrm{wt} \%$ changed drastically the kinetics of phase segregation leading to devices with no decrease in performance over 3000 min thermal treatment. Thin film morphology characterization together with photoluminescence and impedance spectroscopy give further insight into the performance differences between the additives. These results reinforce the conclusion that the compatiblization method is the most promising strategy to engineer highly-efficient thermallystable organic photovoltaics based on solution-processed small molecules.

\section{Introduction}

The development of organic photovoltaics (OPV) using solutionprocessable molecular semiconductors has seen rapid progress in recent years ${ }^{1}$ with solar power conversion efficiencies (PCE) now reaching $10 \% .^{2-4}$ Small-molecule semiconductors, in particular, have recently received significant attention given their advantages over their polymeric counterparts including a reduction of preparation complexity, structural homogeneity, and potentially lower cost. ${ }^{5,6}$ However, the stability of small molecule based OPVs still requires improvement for practical application. ${ }^{7}$ While general OPV device degradation factors such as diffusion of electrode and buffer layers, reactions with oxygen and water, irradiation damage, and mechanical stress have been addressed extensively by engineering approaches, ${ }^{8-}$ 12 a key remaining issue is the intrinsic morphological instability of the bulk heterojunction (BHJ) active layer-which is a metastable blend of disparate donor and acceptor species. ${ }^{13-16}$

Laboratory for Molecular Engineering of Optoelectronic Nanomaterials, École Polytechnique Fédérale de Lausanne (EPFL), Station 6, 1015 Lausanne, Switzerland E-mail: kevin.sivula@epfl.ch

Electronic Supplementary Information (ESI) available: Figures S1-S9, Tables S1-S2 as described in the main text and full experimental/synthetic data. See http://www.rsc.org/suppdata/c7/ta/c7ta05405j/c7ta05405j1.pdf
The relatively high crystallinity of small-molecule $\mathrm{BHJs}^{5,16-18}$ drives donor-acceptor phase segregation, in some cases even at room temperature, ${ }^{19,20}$ which reduces the interfacial area for free charge generation and thus lowers the device performance. $^{21-23}$

In polymer-based BHJs three main approaches have been used to address morphological stability: 1) reducing crystallinity of one of the components via side-chain engineering, ${ }^{24} 2$ ) the insitu cross-linking of polymer chains using functional groups (e.g. oxetane, bromo, vinyl, or azide) incorporated on the solubilizing alkyl side chains, ${ }^{25-28}$ and 3 ) including an additive to reduce the phase segregation. $29,30 \mathrm{~A}$ common additive strategy is to covalently link the donor and acceptor components into a compatiblizer (e.g. a block co-polymer), which is included in the active layer during device fabrication. ${ }^{31-36}$ Donor-acceptor block-copolymers can be envisioned as a single active component for truly thermodynamically stable polymer BHJs. ${ }^{37-}$ 40

Despite the interest in developing strategies for stabilization of polymer-based devices, few reports have addressed morphological stability in small-molecule BHJs even though this is reasonably a greater challenge, due to the relatively high crystallinity in small molecule semiconductors and the absence of polymer entanglement, which leads to negligible mixing between the donor and acceptor. ${ }^{41}$ Reducing the crystallinity of one of the components by side chain engineering, ${ }^{42}$ or by 
including additives such as dimers ${ }^{43}$ or polymers of linked small molecules ${ }^{44}$ has shown some success in slowing the kinetics of phase segregation. However, the more effective cross-linking or compatibilization methods have not been carefully explored for small-molecule BHJ systems. Indeed, it is not clear if the in-situ linking of components in a "cross-linking" approach will be effective in a small molecule BHJ without polymer chains to be linked. Moreover, given the higher crystallinity of small molecule BHJs it is not clear if either approaches can be effective at preventing phase segregation under extended thermal stress without including a large fraction of linking/compatibilizing additives that may affect the electronic properties of the device. Herein, we examine these questions with a well-known small-molecule $\mathrm{BHJ}$ system ${ }^{45}$ based on the donor coded $\mathrm{DPP}(\mathrm{TBFu})_{2}$, and the acceptor $\mathrm{PC}_{61} \mathrm{BM}$, which is used to demonstrate and compare the effectiveness of these two distinct approaches to stabilize the $\mathrm{BHJ}$ and improve the device performance under accelerated thermal stress.

\section{RESUlTS AND DisCUSSION}

The structures of molecules used in this work are shown in Figure 1. The primary $\mathrm{BHJ}$ components $\mathrm{DPP}(\mathrm{TBFu})_{2}$ (donor) and $\mathrm{PC}_{61} \mathrm{BM}$ (acceptor) have previously been established as a common small-molecule system. ${ }^{45-48}$ To demonstrate the in-situ linking approach with this system, an azide functionalized donor component additive, coded as $\mathrm{N}_{3}$-ISL was prepared. The azide group is known to undergo either a thermal or photo-induced nitrene insertion reaction, which has previously been used to crosslink conjugated polymers. ${ }^{25}$ To demonstrate the compatibilizer approach with the primary $\mathrm{BHJ}$ components, a linked version of the donor and acceptor unit was prepared and coded as the compatibilizing additive (CP). Full synthesis and basic characterization of the $\mathrm{N}_{3}-\mathrm{ISL}$ and $C P$ compounds are given in the supporting information. Briefly, the $C P$ additive was strategically synthesized using a mild room temperature condensation reaction between a primary amine functionalized $\mathrm{DPP}(\mathrm{TBFu})_{2}$, and [6,6]-phenyl- $\mathrm{C}_{61}$-butyric acid $\left(\mathrm{PC}_{61} \mathrm{BA}\right)$, while $\mathrm{N}_{3}$-ISL was synthesized via alkylation of 6-(azido)hexyl-bromide on a mono-alkylated DPP(Thiophene $)_{2}$ core, before the Suzuki coupling with a borylated benzofuran unit.

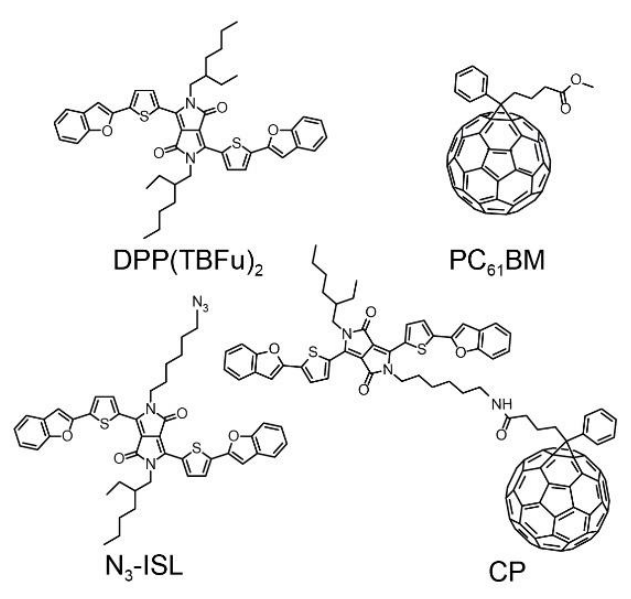

Fig. 1 Molecular Structures of the active materials used in this work.
The UV-vis absorption spectra of all four molecules from Figure 1 is shown in Figure S1, Supporting Information (SI). As expected, the spectrum of $\mathrm{CP}$ consists of the absorption of the DPP(TBFu $)_{2}$ and $\mathrm{PC}_{61} \mathrm{BM}$, while $\mathrm{N}_{3}$-ISL does not differ significantly from the parent donor component suggesting that the optoelectronic properties of the conjugated core are not severely affected. However a slight difference in the shapes of the main absorption peak in spectra of the $\mathrm{N}_{3}-\mathrm{ISL}$ and $\mathrm{CP}$ molecules when cast into thin films suggest that the solid state packing is slightly altered ${ }^{43}$ compared to the parent $\mathrm{DPP}(\mathrm{TBFu})_{2}$. Indeed, differential scanning calorimetry (DSC) of CP showed no obvious phase transitions during its $1^{\text {st }}$ and $2^{\text {nd }}$ heating-cooling cycle (See Figure $\mathrm{S} 2, \mathrm{SI}$ ), suggesting that the $\mathrm{CP}$ is not strongly crystalline in solid-state, in contrast to the primary components, which both exhibit melting transitions characteristic of a semicrystalline morphology in the solid state. On the other hand, the DSC of $\mathrm{N}_{3}$-ISL suggests that the terminal azide undergoes both photo and thermal activation of the nitrene insertion reaction. This is shown by the suppression of phase transitions in an UVtreated ( $254 \mathrm{~nm}$ illumination, exposure for $10 \mathrm{mins}$ ) sample of $\mathrm{N}_{3}$-ISL, whereas non UV-treated $\mathrm{N}_{3}$-ISL showed a series of exothermic and subsequent endothermic transitions peaks during its $1^{\text {st }}$ heating cycle indicative of the thermal activation of the terminal azide ${ }^{49}$ and upon cooling no obvious exotherms were observed. FT-IR spectroscopy also showed a reduction in the intensity of the azide stretch at approximately $2090 \mathrm{~cm}^{-1}$ as UV exposure time is increased (See Figure S3a, SI). Further analysis of the formation of photo- and thermal- reaction products upon addition of $\mathrm{N}_{3}-\mathrm{ISL}$ to a blend of DPP(TBFu $)_{2}$ and $\mathrm{PC}_{61} \mathrm{BM}$ was performed using Gel-Permeation-Chromatography (GPC) and mass spectroscopy (MALDI-TOF MS) (See SI, Figures S3-S5 for full details including experimental procedure and discussion). Briefly, GPC data indicate the presence high molecular weight species after UV and thermal treatments. Moreover, MALDI-TOF MS analysis (See Figure S4 SI) provides evidence of the unselective-nitrene insertion reaction towards both primary blend components by random photo- and thermally-linking the azide group onto the alkyl chains and conjugated backbone of the primary components used in the $\mathrm{BHJ}$ matrix (See Figure S5 SI), along with the photo-dimerization of $\mathrm{PC}_{61} \mathrm{BM}$ under UV illumination. ${ }^{50}$ Importantly the molecular weight of the linked species estimated by GPC matches well with that observed by MS. Overall these results confirm that the $\mathrm{N}_{3}$-ISL can link with both primary $\mathrm{BHJ}$ components under UV or thermal treatment. However, we note that the quantification of the extent of azide reaction is complicated by the absence of data on the molar absorptivity of the linked species (as UV-vis detection was used in GPC).

To test the performance of the additive molecules in their ability to stabilize the morphology of BHJs, standard ITO/PEDOT:PSS/BHJ/Al solar cell devices were prepared with a $\mathrm{BHJ}$ of $\mathrm{DPP}(\mathrm{TBFu})_{2}: \mathrm{PC}_{61} \mathrm{BM}$ at a ratio of $6: 4$ by weight, similar to previously reported conditions. ${ }^{44,45}$ The loading of the CP and $\mathrm{N}_{3}$-ISL additives in the $\mathrm{BHJ}$ matrix were varied (while maintaining the 6:4 ratio of donor:acceptor) and the effect of a UV pretreatment $(10 \mathrm{~min})$ to induce the in-situ linking reaction in as-cast $\mathrm{BHJ}$ with included $\mathrm{N}_{3}$-ISL was also investigated in 
comparison to using thermal treatment only to induce linking. All as-cast devices (spun coat $\mathrm{BHJ}$ with top electrode deposited) were subject to thermal stress at $110^{\circ} \mathrm{C}$ over a period of 3000 $\min (50 \mathrm{~h})$ to drive the crystallization and phase segregation of the primary components, and the current density-voltage (J-V) characteristics were measured periodically under standard 1 sun illumination upon cooling the devices to $20^{\circ} \mathrm{C}$. The power conversion efficiency (PCE) as a function of the thermal treatment time is shown in Figure 2a-c, with respect to the included additive (CP additive, $\mathrm{N}_{3}-\mathrm{ISL}+\mathrm{UV}$ treatment, and $\mathrm{N}_{3}-$ ISL no UV). The J-V curve at the time point corresponding to the highest PCE for each additive condition is shown in Figure 2d-f. Full device performance metrics are also included in the $\mathrm{SI}$ (Table S1). The control device (0 wt\% additive loading, red traces in Figure 2a,d) achieved its highest PCE of 3.0\% after 10 minutes of thermal treatment. The observed performance increase from the as-cast state is expected due to the initial stages of crystallization, which results in an optimum degree of $\mathrm{BHJ}$ phase segregation, and has been previously reported under similar conditions. ${ }^{44}$ Subsequent thermal treatment drives further phase separation ${ }^{51-53}$ and reduces the performance of the device to $1.6 \%$ PCE after $3000 \mathrm{~min}(50 \mathrm{~h})$.

With respect to the compatibilizing linker, adding $1 \mathrm{wt} \%$ of $\mathrm{CP}$ to the $\mathrm{BHJ}$ slightly improved the best PCE to $3.5 \%$ (10 $\mathrm{min}$ thermal treatment) attributed to an increase in short circuit current density $\left(\mathrm{J}_{\mathrm{SC}}\right)$ and fill factor (FF). A similar increase to $3.3 \%$ PCE was also observed at 5 wt\% of CP loading, but interestingly a longer thermal treatment ( $60 \mathrm{~min}$ ) was required to reach this maximum performance. Moreover, both the 1 and 5 wt\% devices showed less decrease in performance over the testing period compared to the control device remaining at 2.4 and 2.7
\% $\mathrm{PCE}$, respectively after $3000 \mathrm{~min}$. In contrast, increasing the $\mathrm{CP}$ loading to $10 \mathrm{wt} \%$ gave a significantly different device behavior. A gradual increase of the PCE was observed as a function of time under thermal stress, saturating at about $2 \%$ PCE after $180 \mathrm{~min}$ and remaining stable over the rest of the testing period. The lower optimum PCE stems from a significant reduction in $\mathrm{J}_{\mathrm{SC}}$ and a reduction of the open circuit voltage $\left(\mathrm{V}_{\mathrm{OC}}\right)$ compared to the control device, as seen on the J-V curve Figure $2 \mathrm{~d}$.

Regarding the $\mathrm{N}_{3}$-ISL additive, firstly we established that a UVtreated control device (treated under UV without any added $\mathrm{N}_{3}-$ ISL, orange curves in Figure $2 \mathrm{~b}, \mathrm{e}$ ) showed a maximum $\mathrm{J}_{\mathrm{SC}}$ of 7.2 $\mathrm{mA} \mathrm{cm}{ }^{-2}$ compared to $8.0 \mathrm{mAcm}^{-2}$ for the control device without UV exposure, and only a slight change in PCE, suggesting that 10 min of UV exposure did not severely affect device performance (however we note that a $30 \mathrm{~min}$ UV treatment did decrease device performance substantially, see Figure S6 SI). While qualitatively similar behavior to the $\mathrm{CP}$ additive was observed when adding $\mathrm{N}_{3}$-ISL to the $\mathrm{BHJ}$, significant differences in the device performance with UV treatment (Figures $2 b$ and e) and without (thermal linking only, Figures $2 \mathrm{c}$ and $\mathrm{f}$ ) are evident.

With 1 wt\% of the $\mathrm{N}_{3}$-ISL additive, no significant change in the optimum device performance was seen regardless of the use of the UV or thermal linking treatment. The maximum PCE was about $3 \%$ after $10 \mathrm{~min}$ at $110{ }^{\circ} \mathrm{C}$ and a decrease of device performance was observed as the thermal treatment time increased. Notably the $1 \mathrm{wt} \%$ devices do seemingly stabilize the $\mathrm{BHJ}$. Indeed, the performance after $3000 \mathrm{~min}$ at $110{ }^{\circ} \mathrm{C}$ was higher in both cases (with and without UV) compared to the control devices. As the additive loading increased further, the device performance changed significantly.
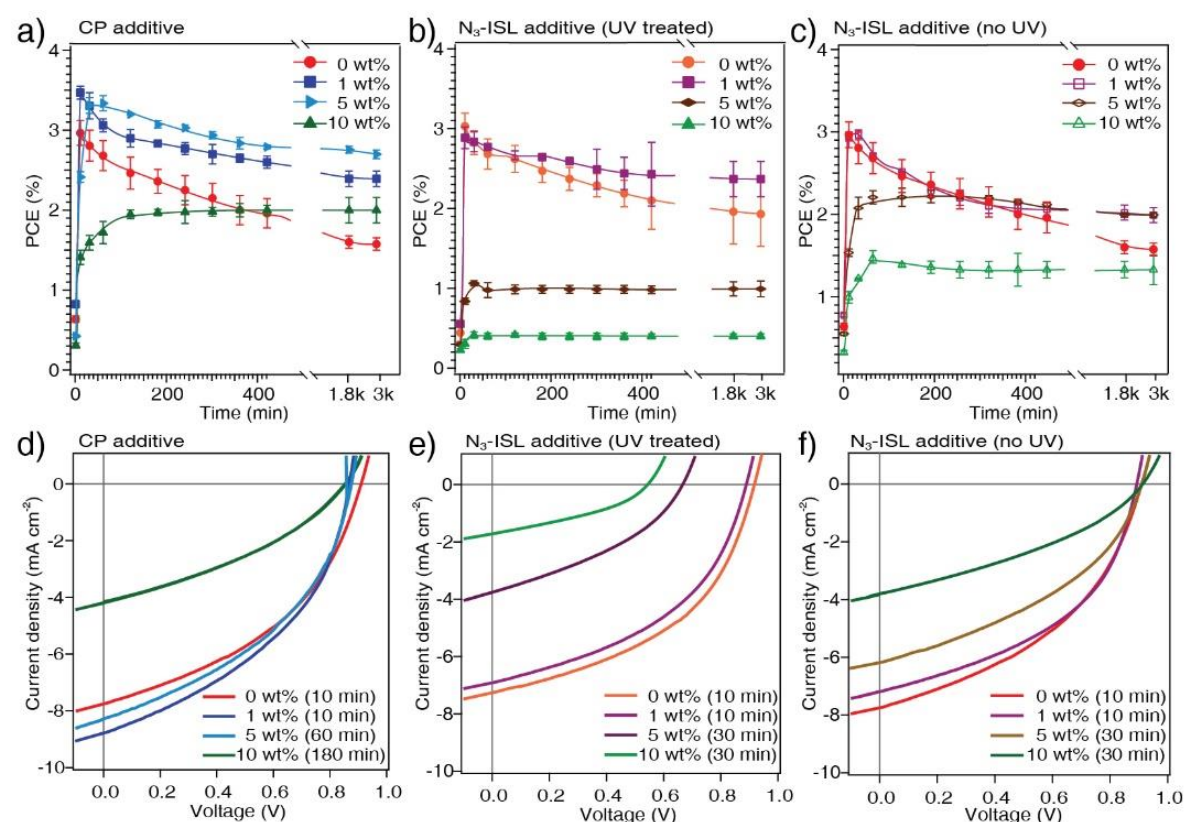

Fig.2 Photovoltaic device performance with respect to the thermal stress at $110^{\circ} \mathrm{C}$. Panels $(\mathrm{a}-\mathrm{c})$ show the power conversion efficiency (PCE) of OPVs based on a $6: 4 \mathrm{DPP}(\mathrm{TBFu})_{2}: \mathrm{PC} \mathrm{C}_{61} \mathrm{BM}$ BHJ with (a) the CP additive (b) the $\mathrm{N}_{3}-\mathrm{ISL}$ with 10 min UV treatment and (c) $\mathrm{N}_{3}-\mathrm{ISL}$ without UV treatment. The loading of the additives are indicated in each case. Panels ( $d$ - $f$ ) show the J-V curves of devices with the BHJ blends using the respective additives at the specified annealing time (given in parentheses) to obtain its maximum PCE. 
Similar to the CP additive, devices at 5 and $10 \mathrm{wt} \% \mathrm{~N}_{3}-\mathrm{ISL}$ required a longer time at $110^{\circ} \mathrm{C}$ to reach the maximum $\mathrm{PCE}$ compared to the control devices. Moreover, at both 5 and 10 wt\% of the $\mathrm{N}_{3}$-ISL additive, a stable PCE with respect to thermal treatment time was achieved after ca. $120 \mathrm{~min}$ (with or without UV treatment). However, a larger decrease in maximum device performance was observed when UV treatment was used, reaching a PCE of only $1 \%$ (5 wt\%) and $0.4 \%$ (10 wt\%), while a better maximum performance of $2.4 \%(5 \mathrm{wt} \%)$ and $1.5 \%$ (10 wt\%) was recorded for non-UV cured devices. For the case of the UV treated devices, the lower performance was attributed to a decrease in the $\mathrm{J}_{\mathrm{SC}}, \mathrm{FF}$, and $\mathrm{V}_{\mathrm{OC}}$ compared to control devices (Figure 2e), while interestingly, without UV treatment the difference was mainly due a decreased $J_{S C}$ only (Figure $2 f$ ). These results strongly suggest a different functioning of the $\mathrm{N}_{3}$ ISL additive with or without the UV treatment, which will be discussed later.

While it is clear that both the additives can improve the device stability under thermal stress, differences in the optimum additive loading and the maximum PCE obtained suggest dissimilarity in the evolution of the BHJ morphology with respect to the additive used. Analyzing the topography of the $\mathrm{BHJ}$ thin films by atomic force microscopy (AFM) was next performed to provide insight into morphological differences. Figure 3 displays the topography of the $6: 4$ donor:acceptor BHJs after thermal treatment at $110{ }^{\circ} \mathrm{C}$ for $3000 \mathrm{~min}$ (main images) compared to the as-cast state (image insets) for 0,1 , and 10 wt $\%$ of the CP additive and 0,1 and 10 wt\% of the $\mathrm{N}_{3}$-ISL additive with a $10 \mathrm{~min}$ UV treatment applied before the thermal treatment.

A relatively featureless morphology was observed in as-cast thin films across all additive loadings, but upon heating the BHJs at
$110{ }^{\circ} \mathrm{C}$ for 3000 min clear differences were observed. Without additive and without UV treatment (Figure 3a), the morphology exhibited the expected haystack morphology with needle-like features corresponding to crystalline domains of the components. ${ }^{44}$ It has been established that the driving force for phase segregation in this $\mathrm{BHJ}$ is the crystallization of $\operatorname{DPP}(\mathrm{TBFu})_{2}$, which is reported to occur at temperatures as low as the cold crystallization temperature of approximately $70^{\circ} \mathrm{C} .46$ The morphology of the $\mathrm{BHJ}$ with $1 \mathrm{wt} \%$ of the $\mathrm{CP}$ additive (Figure 3b) was significantly less rough than the control after the thermal treatment, but crystalline domains of a similar size as in the control can still be observed, suggesting a degree of phase segregation similar to the control, which is consistent with the evolution of the PCE seen at this condition. In contrast, at 10 wt\% CP loading (Figure 3c) micron-sized needle-like features are completely suppressed after the thermal treatment. However, a slight coarsening of the grains from the as-cast condition can be seen, suggesting an increase in crystallinity during the 3000 min thermal treatment, consistent with the gradual increase in the PCE.

With respect to the $\mathrm{N}_{3}$-ISL additive we first note that the phasesegregated morphology containing needle-like features was also observed for the UV-treated BHJ without additive (Figure 3d) but with smaller-sized crystalline domains, suggesting that the UV treatment alone has an effect on the nucleation and growth of the crystalline domains. Upon loading $\mathrm{N}_{3}-\mathrm{ISL}$ at even $1 \mathrm{wt} \%$ the formation of these needle-like domains was clearly suppressed. The resulting $\mathrm{BHJ}$ after thermal stress appeared with a larger roughness when using $1 \mathrm{wt} \% \mathrm{~N}_{3}$-ISL (Figure 3e) compared to $10 \mathrm{wt} \%$ (Figure $3 \mathrm{f}$ ), which suggests a different evolution of the phase separation consistent with the OPV results.

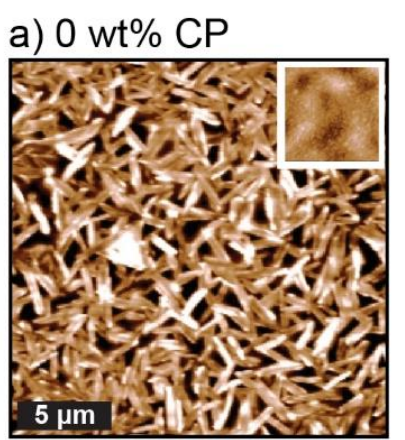

b) $1 \mathrm{wt} \% \mathrm{CP}$
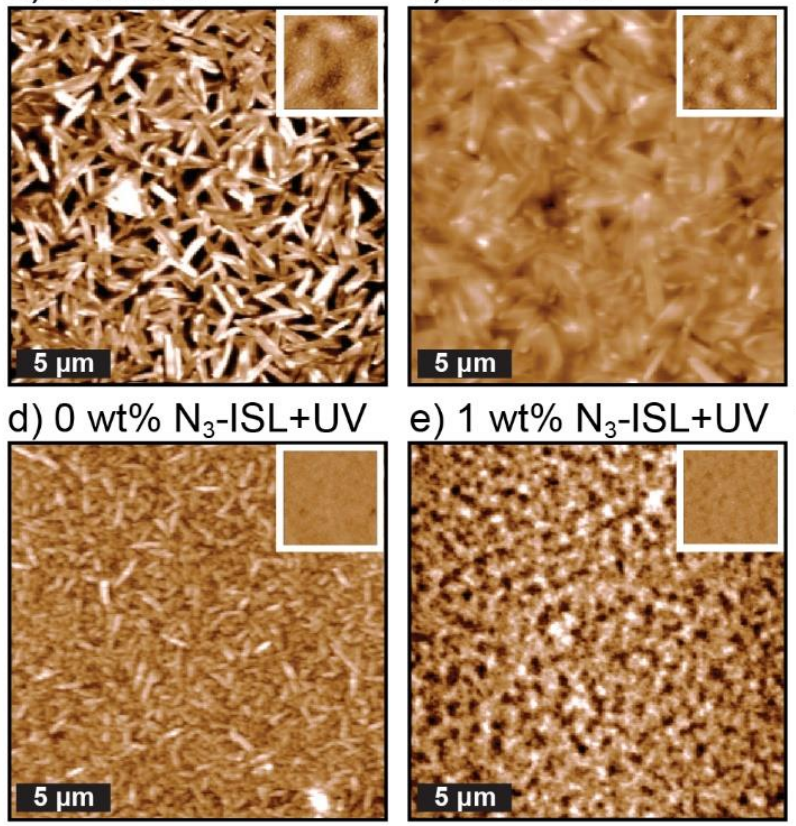

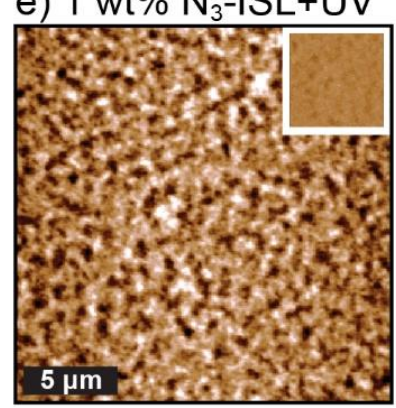

c) $10 \mathrm{wt} \% \mathrm{CP}$
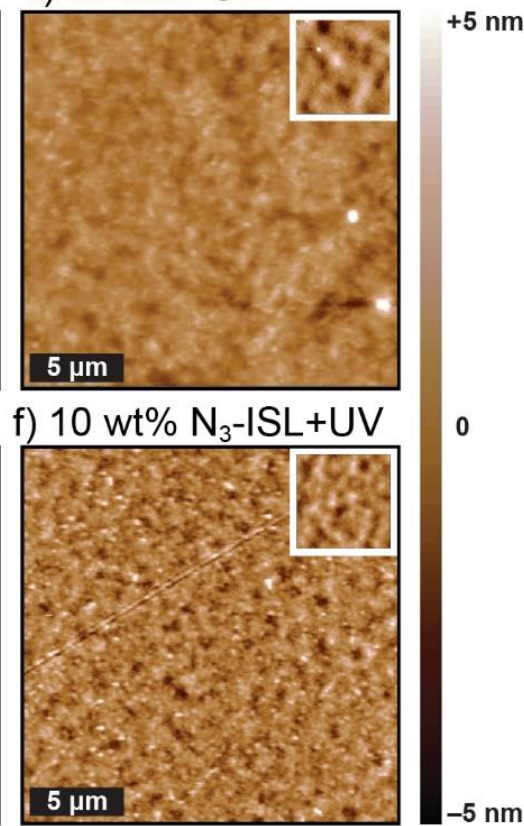

Fig. 3 Thin Film topography by AFM of the 6:4 donor:acceptor blends after $3000 \mathrm{~min}$ at $110^{\circ} \mathrm{C}$ (main panels) and as spun-cast from Chloroformsolutions (panel insets). a) with no additive b) with $1 \mathrm{wt} \% \mathrm{CP}, \mathrm{c}$ ) with $10 \mathrm{wt} \% \mathrm{CP}$, d) with no additive but with $10 \mathrm{~min}$ UV treatment before thermal stress, e) with $1 \mathrm{wt} \%$ N3-ISL + UV and f) with $10 \mathrm{wt} \%$ N3-ISL with UV treatment. 
The topography results together with the device performance suggest that the additives have an effect on the crystallinity of the BHJ. To confirm this, DSC was performed on 6:4 blends of $\mathrm{DPP}(\mathrm{TBFu})_{2}: \mathrm{PC}_{61} \mathrm{BM}$ with varying amounts of the additives. The first heating scan of the as-cast blends is shown in Figure 4a. While a melting transition of the crystalized DPP $(\mathrm{TBFu})_{2}$ in the $\mathrm{BHJ}$ is seen to onset at ca. $190^{\circ} \mathrm{C}$, this transition was suppressed with the addition of $10 \mathrm{wt} \%$ of either additive, reducing the enthalpy of the transition by about half with $\mathrm{N}_{3}-\mathrm{ISL}$ and by a factor of three with the CP additive (See Table S2, SI). Increasing the amount of the CP additive (to $50 \mathrm{wt} \%$ ) led to an almost complete suppression of the melting transition, however about $20 \%$ of the original melting enthalpy remained when $50 \mathrm{wt} \%$ of the $\mathrm{N}_{3}$-ISL additive was used with a 10 min UV treatment. This suggests that the $\mathrm{CP}$ additive exhibits a qualitatively stronger ability to disrupt the crystallinity of the $\mathrm{DPP}(\mathrm{TBFu})_{2}$ compared to the $\mathrm{N}_{3}-\mathrm{ISL}$ additive, consistent with the rougher morphology observed after thermal stress with the $\mathrm{N}_{3}-\mathrm{ISL}$ at $10 \mathrm{wt} \%$ loading compared to $10 \mathrm{wt} \% \mathrm{CP}$ (as seen in Figure 2). However, the presence of large crystalline domains in the thermally stressed 1 wt\% CP BHJ film morphology, but the absence of these domains in the $1 \mathrm{wt} \% \mathrm{~N}_{3}$-ISL film suggests that while the $\mathrm{CP}$ may disrupt the $\pi$ - $\pi$ stacking of the DPP(TBFu $)_{2}$ to a greater degree, it does not prevent phase segregation as effectively as the $\mathrm{N}_{3}$ ISL linker. This is emphasized in the OPV results where $5 \mathrm{wt} \%$ of the $\mathrm{CP}$ has a less drastic effect on the evolution of the PCE compared to $5 \mathrm{wt} \%$ of $\mathrm{N}_{3}$-ISL.

Despite the differences in the additive behavior, overall the DSC results suggest that crystallization of the $\mathrm{BHJ}$ components can be suppressed even under extreme thermal treatment, to further demonstrate this aspect, thin films were annealed at $240{ }^{\circ} \mathrm{C}$ (above the melting transition of DPP $(\mathrm{TBFu})_{2}$ ) and slowly cooled, in order to strongly drive phase segregation. Optical microscope images of the films are shown in Figure S7, SI. As expected, while the control film without additives crystallized with large $(>5 \mu \mathrm{m})$ domains (slightly smaller, $\sim 2 \mu \mathrm{m}$, for UV treated films without additive), the films with $10 \mathrm{wt} \%$ additives showed significantly smaller domains, mirroring the morphology of the films treated at $110^{\circ} \mathrm{C}$. This data show, that despite that the melting enthalpy remaining at $10 \mathrm{wt} \%$ additive loading, the thin film BHJ morphology can be stabilized even in under extreme conditions.

As it is important to better understand the optoelectronic differences between the two additives, photoluminescence $(\mathrm{PL})$ spectroscopy was next performed on the $\mathrm{BHJ}$ films with varying the additive loading. Indeed, the PL intensity is known to be affected by the proximity/size of the donor and acceptor domains, where greater phase segregation leads to more PL emission from the donor upon its excitation. The PL spectra upon excitation at $532 \mathrm{~nm}$ show a main peak from the emission of DPP $(\mathrm{TBFu})_{2}$ around $820 \mathrm{~nm}$ (see Figure S8, SI). The relative amount of emission compared to control $\mathrm{BHJ}$ s without additives is summarized in Figure $4 \mathrm{~b}$ as a function of the additive loading. While as-cast BHJs with added $\mathrm{N}_{3}$-ISL only show a slight decline in the PL spectra, implying that this additive does not significantly alter the as-cast $\mathrm{BHJ}$ morphology, the $\mathrm{CP}$ additive has a drastic effect on the PL of the as-cast $\mathrm{BHJ}$ film at just $1 \mathrm{wt} \%$ loading, giving only $35 \%$ of the emission compared to the control, consistent with the formation of a more mixed donor:acceptor $\mathrm{BHJ}$ after spin casting from solvent. After thermally treating the film at $110^{\circ} \mathrm{C}$ for $1 \mathrm{~h}$, the $1 \mathrm{wt} \% \mathrm{CP} \mathrm{BHJ}$ decreased in $\mathrm{PL}$ intensity to $50 \%$ (relative to the control) consistent with the difference in phase segregation observed in the AFM topography. Higher loadings of CP gave lower PL after annealing consistent with the suppression of phase separation. Interestingly, after annealing the BHJs with the $\mathrm{N}_{3}$-ISL additive a greater relative drop in the $\mathrm{PL}$ is seen in the UV treated films compared to BHJs with $\mathrm{N}_{3}$-ISL but without UV pretreatment. This further indicates a different behavior between the thermal linking and the UV linking approaches.

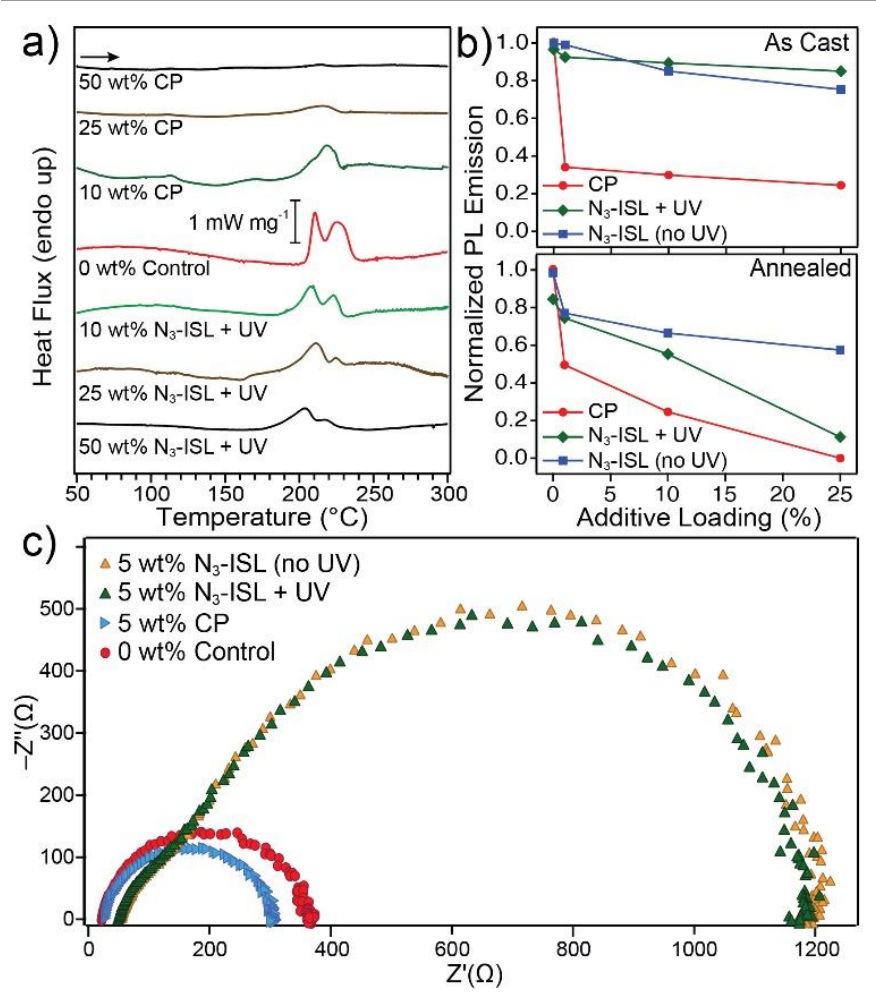

Fig. 4 a) First DSC heating scans of drop cast BHJ films (6:4 donor:acceptor) with the respective additives. Blends with N3-ISL were UV treated for $10 \mathrm{~min}$. b.) Normalized (integrated) PL emission of as cast (top panel) and thermally annealed (bottom panel 110 ${ }^{\circ} \mathrm{C}, 1 \mathrm{~h}$ ) of 6:4 donor:acceptor blend thin-films is shown against additive loading. c) Nyquist plots of impedance spectra measured under 1 Sun illumination at open circuit conditions of thermally annealed $\left(2 \mathrm{~h}, 110^{\circ} \mathrm{C}\right)$ devices with respective additives and UV curing conditions.

For a final comparison of the additives, we performed impedance spectroscopy (IS) on thermally treated $\left(110^{\circ} \mathrm{C}, 2 \mathrm{~h}\right)$ devices, under illumination and at open circuit. Nyquist plots are shown in Figure 4c. The control device exhibited a single RC process, which has been previously ascribed to $\mathrm{BHJ}$ recombination under these conditions. ${ }^{54,55} \mathrm{~A}$ device containing 5 wt\% of CP (and which exhibited higher PCE compared to the control device) gave a similar behavior in IS, with a lower recombination resistance, consistent with a more intermixed phase (as compared to the reference device) where more free charges are generated. ${ }^{55}$ In stark contrast, the $5 \mathrm{wt} \% \mathrm{~N}_{3}$-ISL device that underwent UV pretreatment exhibited an additional semicircle in the Nyquist plot at low frequency with a considerably higher associated resistivity. While this may be expected due to the poor PCE of this device compared to the 
control, notably we found that a device with $5 \mathrm{wt} \% \mathrm{~N}_{3}-\mathrm{ISL}$ that did not undergo the UV treatment (and that had a similar PCE to the control device) exhibited a similarly-large RC process as shown in Figure 4c. The presence of this large second semicircle can be attributed to trap state processes within the active layer, ${ }^{56}$ which is reasonable given the confirmed presence of randomly linked species formed by the reaction of the azide on $\mathrm{N}_{3}$-ISL (by MALDI-TOF MS, Figure S4). However, the seemingly similar IS behavior of the $5 \mathrm{wt} \% \mathrm{~N}_{3}$-ISL devices with and without the UV treatment contrasts the very different behavior that these two conditions give with respect to device PCE and the PL. A reasonable explanation for this difference is as follows: In both the thermal and UV linking approaches the azide linker reacts randomly forming linked $\mathrm{BHJ}$ components that retard phase segregation and in both cases introduce the presence of trapping states in the $\mathrm{BHJ}$ which reduce the device performance (Indeed we note that previous work on using random $\mathrm{BHJ}$ crosslinking methods on polymer-based OPVs have pointed out that the reactions may provoke the breaking of the conjugated polymer backbone, disrupt charge transport, and reduce performance). ${ }^{26}, 27,49,57-59$ However since the UV activated linking clearly leads to a poorer performance the nature of the linking points or the linked species is reasonably somehow different. In fact careful analysis of the GPC and MALDI-TOF MS data between the UV linking and thermal linking approaches (Figures S3 and S4, SI), do suggest clear differences. Firstly, the presence of dimerized $\mathrm{PC}_{61} \mathrm{BM}$ (see structure Figure $\mathrm{S} 5, \mathrm{SI}$ ) under UV treatment and not under thermal conditions is observed by MS. While breaking of the conjugated fullerene unit is known to cause the formation of traps ${ }^{60,61}$ the presence of dimerized fullerene alone does not fully explain why the UV treatment suffers a poorer performance, as the control device (without $\mathrm{N}_{3}$-ISL but with $10 \mathrm{~min}$ UV treatment) performed similar to the control device without UV. However, it has been suggested that UV excitation of azide derivatives results in an alternative, highly reactive reaction pathway of the nitrene insertion linking as compared to thermal activation (which has been characterized as more selective and milder). ${ }^{49,} 62$ Indeed the GPC results (Figure S3) show a higher concentration of linked products in the UV treated films compared to the thermally treated films. Thus we hypothesize that UV excitation causes the formation of important deep traps at a faster rate in the presence of the $\mathrm{N}_{3}$-ISL additive. These deep traps result in a lower device $\mathrm{V}_{\mathrm{OC}}$ when using the UV treatment and thus the lower PCE. Moreover, we note further that at low loadings (1 wt\%) of the $\mathrm{N}_{3}-\mathrm{ISL}$, when the linking reaction is not sufficient to prevent crystallization of the donor and acceptor phases in the $\mathrm{BHJ}$, the few linked species could be excluded via crystallization to the grain boundaries or amorphous regions where they will have less of an effect on the charge transport through the pure phases. In contrast, when the $\mathrm{N}_{3}$-ISL is at a sufficiently high concentration in the $\mathrm{BHJ}$ to arrest the phase segregation in the film (about 5 wt\%) these charge trapping species cannot be excluded and the PL and device performance drops. Then the different nature of the linked species when including the UV treatment (perhaps more linking on the fullerene), compared to the thermal treatment leads to the drastic difference in performance.

\section{Conclusions}

In summary, two additives, a compatibilizer (CP) and an azide functionalized in-situ linker ( $\left.\mathrm{N}_{3}-\mathrm{ISL}\right)$, were prepared to examine the possibility to stabilize BHJ OPVs prepared from solutionprocessed crystalline small molecules. The device results show that both additives have the ability to stop the phase segregation of the donor and acceptor in the $\mathrm{BHJ}$ when subject to thermal stress for an extended period. While the $\mathrm{N}_{3}-\mathrm{ISL}$ additive required only $5 \mathrm{wt} \%$ loading to arrest phase segregation, altering the azide reaction mechanism by using UVinduced linking versus thermal induced linking gave significantly different performance attributed to a likely difference in reaction products, and UV treated devices performed poorer than thermally linked ones. We note that both compatibilizing and homo-dimer species are produced with N3-ISL, and the specific effect of each of the produced species cannot be separately determined, which is a drawback of this approach. Moreover, the presence of the non-specific linked species in both cases led to increased $\mathrm{BHJ}$ charge trapping as shown by $\mathrm{PL}$ and IS spectroscopies, and reduced performance compared to the $\mathrm{CP}$ additive. Indeed, including 5 wt\% of the $\mathrm{CP}$ additive retarded the $\mathrm{BHJ}$ phase segregation and led to the highest $\mathrm{PCE}$ of $2.8 \%$ after $3000 \mathrm{~min}$ of thermal treatment at $110{ }^{\circ} \mathrm{C}$. Moreover $10 \mathrm{wt} \%$ of the CP additive changed drastically the kinetics of phase segregation leading to devices that saturated in performance at $2 \%$ after $120 \mathrm{~min}$ with no decrease for 3000 min (the length of our test). In this case the slower crystallization and phase segregation of the $\mathrm{BHJ}$ from the ascast state may also prove to be an advantage in offering the ability to avoid overshoot in the device annealing. Moreover, the observed control over phase segregation in the meltannealed films with CP could potentially allow for melt processing of the $\mathrm{BHJ}$, which is currently being investigated in our labs. Overall based on the results presented, employing the $\mathrm{CP}$ additives is a preferred strategy to stabilize the bulk heterojunction. Further efforts should be directed toward optimizing the CP strategy for other small-molecule systems to potentially enable solvent-free roll-to-roll processing of highly efficiency and stable OPVs.

\section{Conflicts of interest}

There are no conflicts of interest to declare.

\section{Acknowledgements}

We thank the European Research Commission (ERC starting grant "CEMOS" Project 336506) for financial support of this work.

\section{Notes and references}


1 A. Mishra and P. Bäuerle, Angew. Chem. Int. Ed., 2012, 51 2020-2067.

2 Q. Zhang, B. Kan, F. Liu, G. Long, X. Wan, X. Chen, Y. Zuo, W. Ni, H. Zhang, M. Li, Z. Hu, F. Huang, Y. Cao, Z. Liang, M. Zhang, T. P. Russell and Y. Chen, Nat. Photonics, 2015, 9, 35-41.

3 B. Kan, M. Li, Q. Zhang, F. Liu, X. Wan, Y. Wang, W. Ni, G. Long, X. Yang, H. Feng, Y. Zuo, M. Zhang, F. Huang, Y. Cao, T. P. Russell and Y. Chen, J. Am. Chem. Soc., 2015, 137, 3886-3893.

4 B. Kan, Q. Zhang, M. Li, X. Wan, W. Ni, G. Long, Y. Wang, X. Yang, H. Feng and Y. Chen, J. Am. Chem. Soc., 2014, 136, 15529-15532.

5 S. D. Collins, N. A. Ran, M. C. Heiber and T.-Q. Nguyen, Adv. Energy Mater., 2017, 7, 1602242.

6 T. P. Osedach, T. L. Andrew and V. Bulovic, Energy Environ. Sci., 2013, 6, 711-718.

7 P. Cheng and X. Zhan, Chem. Soc. Rev., 2016, 45, 2544-2582.

8 C. Müller, Chem. Mater., 2015, 27, 2740-2754.

9 P. Cheng and X. Zhan, Mater. Horiz., 2015, 2, 462-485.

10 S. Savagatrup, A. D. Printz, T. F. O'Connor, A. V. Zaretski, D. Rodriquez, E. J. Sawyer, K. M. Rajan, R. I. Acosta, S. E. Root and D. J. Lipomi, Energy Environ. Sci., 2015, 8, 55-80.

11 A. D. Scaccabarozzi and N. Stingelin, J. Mater. Chem. A, 2014, 2, 10818-10824.

12 M. Jørgensen, K. Norrman, S. A. Gevorgyan, T. Tromholt, B. Andreasen and F. C. Krebs, Adv. Mater., 2012, 24, 580-612.

13 N. Stingelin, Polym. Int., 2012, 61, 866-873.

14 A. J. Moulé and K. Meerholz, Adv. Funct. Mater., 2009, 19, 3028-3036.

15 J. Peet, A. J. Heeger and G. C. Bazan, Acc. Chem. Res., 2009, 42, 1700-1708.

16 B. A. Collins, J. R. Tumbleston and H. Ade, J. Phys. Chem. Lett., 2011, 2, 3135-3145.

17 I. Fraga Domínguez, A. Distler and L. Lüer, Adv. Energy Mater., 2017, 7, 1601320.

18 I. Cardinaletti, J. Kesters, S. Bertho, B. Conings, F. Piersimoni, J. D'Haen, L. Lutsen, M. Nesladek, B. Van Mele, G. Van Assche, K. Vandewal, A. Salleo, D. Vanderzande, W. Maes and J. V. Manca, J. Photonics Energy, 2014, 4, 040997-040997.

19 W. H. Lee, J. A. Lim, D. H. Kim, J. H. Cho, Y. Jang, Y. H. Kim, J. I. Han and K. Cho, Adv. Funct. Mater., 2008, 18, 560-565.

20 P. E. Keivanidis, F. Laquai, I. A. Howard and R. H. Friend, Adv. Funct. Mater., 2011, 21, 1355-1363.

21 C. J. Schaffer, C. M. Palumbiny, M. A. Niedermeier, C. Jendrzejewski, G. Santoro, S. V. Roth and P. MüllerBuschbaum, Adv. Mater., 2013, 25, 6760-6764.

22 M. T. Dang, L. Hirsch, G. Wantz and J. D. Wuest, Chem. Rev., 2013, 113, 3734-3765.

23 Y. Huang, E. J. Kramer, A. J. Heeger and G. C. Bazan, Chem. Rev., 2014, 114, 7006-7043.

24 Z. Li, F. Wu, H. Lv, D. Yang, Z. Chen, X. Zhao and X. Yang, Adv. Mater., 2015, 27, 6999-7003.

25 J. E. Carle, B. Andreasen, T. Tromholt, M. V. Madsen, K. Norrman, M. Jorgensen and F. C. Krebs, J. Mater. Chem., 2012, 22, 24417-24423.

26 Y.-J. Cheng, C.-H. Hsieh, P.-J. Li and C.-S. Hsu, Adv. Funct. Mater., 2011, 21, 1723-1732.
27 J. W. Rumer and I. McCulloch, Mater. Today, 2015, 18, 425435.

28 G. Wantz, L. Derue, O. Dautel, A. Rivaton, P. Hudhomme and C. Dagron-Lartigau, Polym. Int., 2014, 63, 1346-1361.

29 B. C. Schroeder, Z. Li, M. A. Brady, G. C. Faria, R. S. Ashraf, C. J. Takacs, J. S. Cowart, D. T. Duong, K. H. Chiu, C.-H. Tan, J. T. Cabral, A. Salleo, M. L. Chabinyc, J. R. Durrant and I. McCulloch, Angew. Chem. Int. Ed., 2014, 53, 12870-12875.

$30 \mathrm{~J}$. Li, X. Zhu, T. Yuan, J. Shen, J. Liu, J. Zhang and G. Tu, ACS Appl. Mater. Interfaces, 2017, 9, 6615-6623.

31 K. Yuan, L. Chen and Y. Chen, Polym. Int., 2014, 63, 593-606.

32 D. Kipp, R. Verduzco and V. Ganesan, Mol. Syst. Des. Eng., 2016, 1, 353-369.

33 K. Sivula, Z. T. Ball, N. Watanabe and J. M. J. Fréchet, $A d v$. Mater., 2006, 18, 206-210.

34 J. B. Kim, K. Allen, S. J. Oh, S. Lee, M. F. Toney, Y. S. Kim, C. R. Kagan, C. Nuckolls and Y.-L. Loo, Chem. Mater., 2010, 22, 5762-5773.

35 F. Lombeck, A. Sepe, R. Thomann, R. H. Friend and M. Sommer, ACS Nano, 2016, 10, 8087-8096.

36 J. E. Slota, E. Elmalem, G. Tu, B. Watts, J. Fang, P. M. Oberhumer, R. H. Friend and W. T. S. Huck, Macromolecules, 2012, 45, 1468-1475.

37 C. Guo, Y.-H. Lin, M. D. Witman, K. A. Smith, C. Wang, A. Hexemer, J. Strzalka, E. D. Gomez and R. Verduzco, Nano Lett., 2013, 13, 2957-2963.

38 Y. Lee and E. D. Gomez, Macromolecules, 2015, 48, 73857395.

39 A. Gasperini, M. Johnson, X. Jeanbourquin, L. Yao, A. Rahmanudin, N. Guijarro and K. Sivula, Polym. Chem., 2017, 8, 824-827.

40 D. Kipp, J. Mok, J. Strzalka, S. B. Darling, V. Ganesan and R. Verduzco, ACS Macro Lett., 2015, 4, 867-871.

41 S. D. Oosterhout, V. Savikhin, J. Zhang, Y. Zhang, M. A. Burgers, S. R. Marder, G. C. Bazan and M. F. Toney, Chem. Mater., 2017, 29, 3062-3069.

42 J. Min, C. Cui, T. Heumueller, S. Fladischer, X. Cheng, E. Spiecker, Y. Li and C. J. Brabec, Adv. Energy Mater., 2016, 6, 1600515.

43 X. A. Jeanbourquin, A. Rahmanudin, A. Gasperini, E. Ripaud, X. Yu, M. Johnson, N. Guijarro and K. Sivula, J. Mater. Chem. A, 2017, 5, 10526-10536.

44 A. Gasperini, X. A. Jeanbourquin, A. Rahmanudin, X. Yu and K. Sivula, Adv. Mater., 2015, 27, 5541-5546.

45 B. Walker, A. B. Tamayo, X.-D. Dang, P. Zalar, J. H. Seo, A. Garcia, M. Tantiwiwat and T.-Q. Nguyen, Adv. Funct. Mater., 2009, 19, 3063-3069.

46 A. Sharenko, M. Kuik, M. F. Toney and T.-Q. Nguyen, Adv. Funct. Mater., 2014, 24, 3543-3550.

47 A. Viterisi, F. Gispert-Guirado, J. W. Ryan and E. Palomares, J. Mater. Chem., 2012, 22, 15175.

48 D. Fernandez, A. Viterisi, J. W. Ryan, F. Gispert-Guirado, S. Vidal, S. Filippone, N. Martin and E. Palomares, Nanoscale, 2014, 6, 5871-5878.

49 L. Derue, O. Dautel, A. Tournebize, M. Drees, H. Pan, S. Berthumeyrie, B. Pavageau, E. Cloutet, S. Chambon, L. Hirsch, 
A. Rivaton, P. Hudhomme, A. Facchetti and G. Wantz, Adv. Mater., 2014, 26, 5831-5838.

50 A. Dzwilewski, T. Wågberg and L. Edman, J. Am. Chem. Soc., 2009, 131, 4006-4011.

51 S. B. Dkhil, M. Pfannmöller, M. I. Saba, M. Gaceur, H. Heidari, C. Videlot-Ackermann, O. Margeat, A. Guerrero, J. Bisquert, G. Garcia-Belmonte, A. Mattoni, S. Bals and J. Ackermann, Adv. Energy Mater., 2017, 7, 1601486.

52 K. Tada, Sol. Energy Mater. Sol. Cells, 2015, 132, 15-20.

53 C.-G. Wu, C.-H. Chiang and H.-C. Han, J. Mater. Chem. A, 2014, 2, 5295-5303.

54 W. L. Leong, S. R. Cowan and A. J. Heeger, Adv. Energy Mater., 2011, 1, 517-522.

55 D. Credgington and J. R. Durrant, J. Phys. Chem. Lett., 2012, 3 , 1465-1478.

56 L. Burtone, J. Fischer, K. Leo and M. Riede, Phys. Rev. B, 2013, 87, 045432.

57 C.-Y. Nam, Y. Qin, Y. S. Park, H. Hlaing, X. Lu, B. M. Ocko, C. T. Black and R. B. Grubbs, Macromolecules, 2012, 45, 2338-2347.

58 L. Chen, X. Li and Y. Chen, Polym. Chem., 2013, 4, 5637-5644.

59 S. Miyanishi, K. Tajima and K. Hashimoto, Macromolecules, 2009, 42, 1610-1618.

60 T. Heumueller, W. R. Mateker, A. Distler, U. F. Fritze, R. Cheacharoen, W. H. Nguyen, M. Biele, M. Salvador, M. von Delius, H.-J. Egelhaaf, M. D. McGehee and C. J. Brabec, Energy Environ. Sci., 2016, 9, 247-256.

61 Z. Li, H. C. Wong, Z. Huang, H. Zhong, C. H. Tan, W. C. Tsoi, J. S. Kim, J. R. Durrant and J. T. Cabral, Nat. Commun., 2013, 4 2227.

62 F.-J. Kahle, C. Saller, A. Köhler and P. Strohriegl, Adv. Energy Mater. DOI: 10.1002/aenm.201700306 